Supplement of Hydrol. Earth Syst. Sci., 22, 5191-5210, 2018

https://doi.org/10.5194/hess-22-5191-2018-supplement

(C) Author(s) 2018. This work is distributed under

the Creative Commons Attribution 4.0 License.

(c) (1)

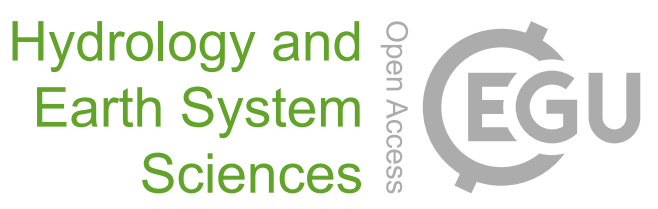

Supplement of

\title{
Breeze effects at a large artificial lake: summer case study
}

Maksim Iakunin et al.

Correspondence to: Maksim Iakunin (miakunin@uevora.pt)

The copyright of individual parts of the supplement might differ from the CC BY 4.0 License. 
Figure S1. Comparison of Meso-NH and radiosonde air temperature profiles. Each plot represents corresponding balloon launch.
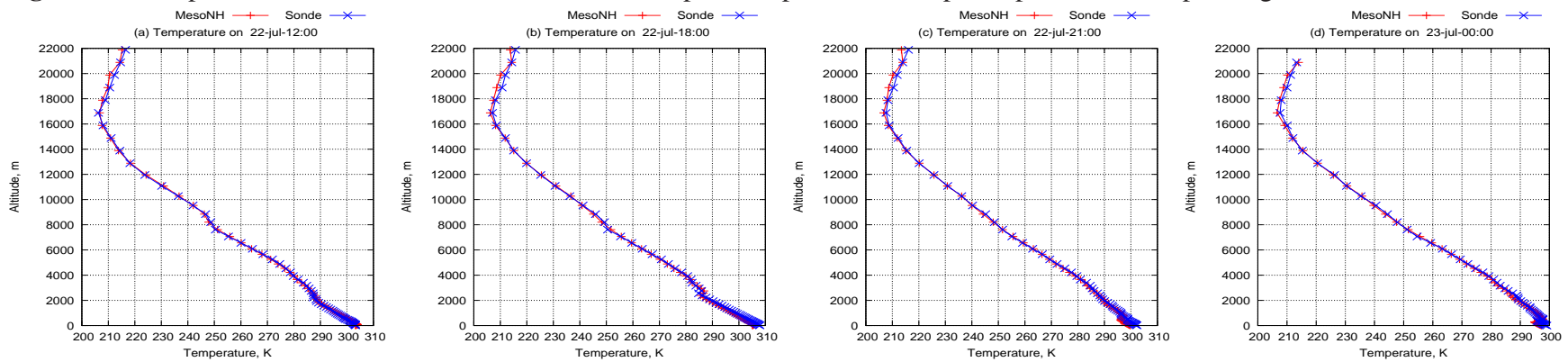

MesoNH + Sonde
Temperature on 23 -jul-03:00
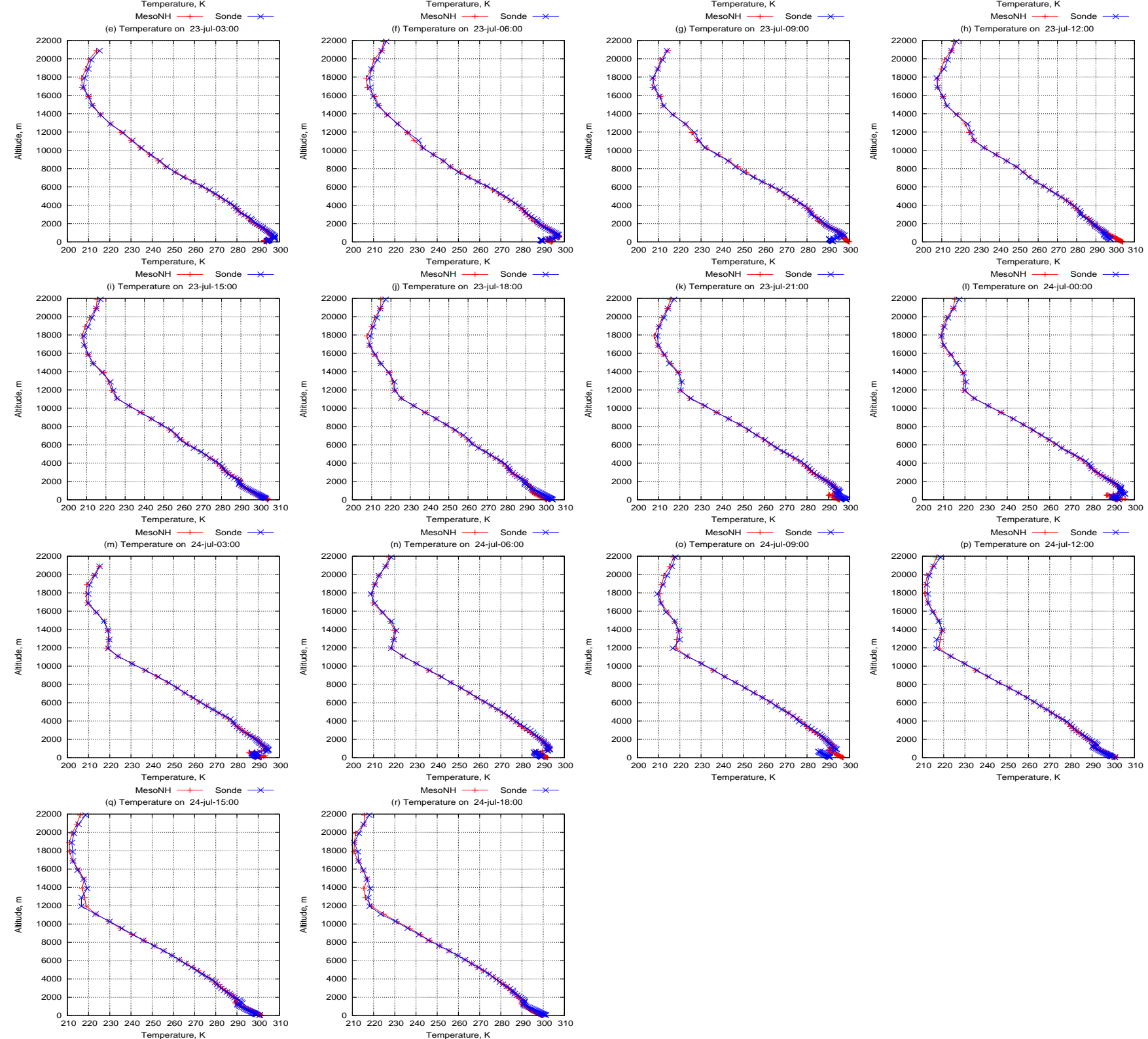
Figure S2. Comparison of Meso-NH and radiosonde wind speed profiles. Each plot represents corresponding balloon launch.

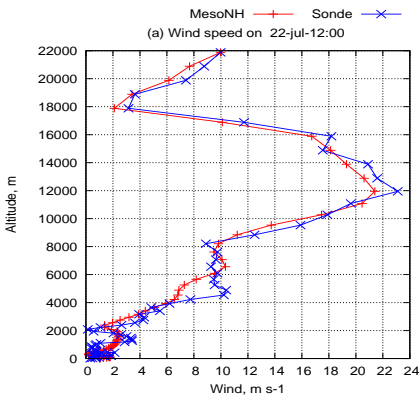

MesoNH + Sonde

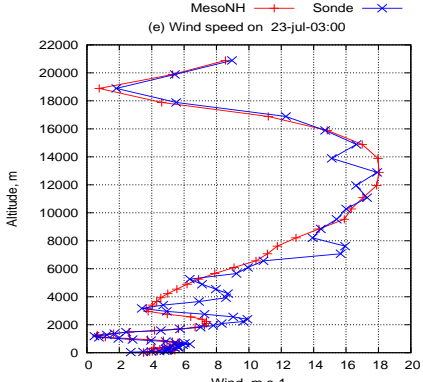

Wind, $\mathrm{m} \mathrm{s}-1$
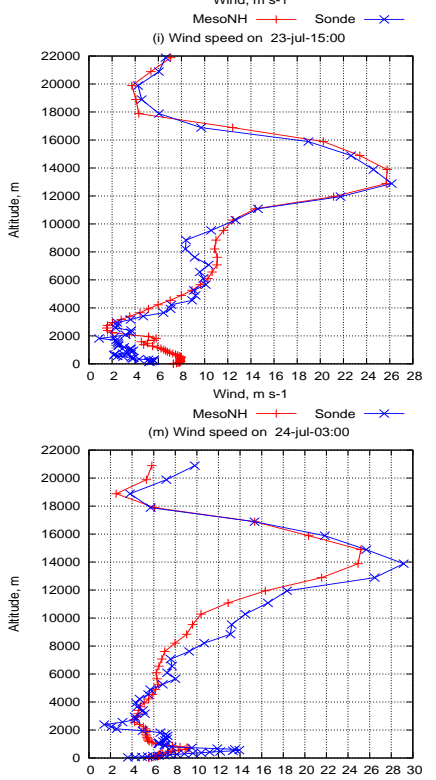
Wind, $\mathrm{m} \mathrm{s}$-1

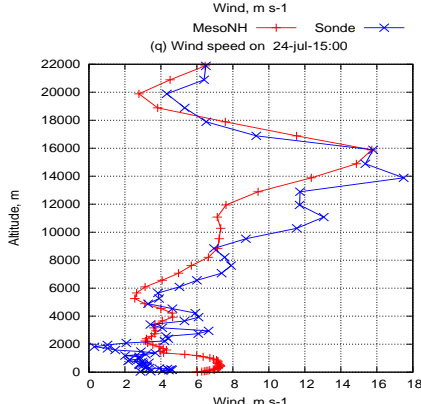

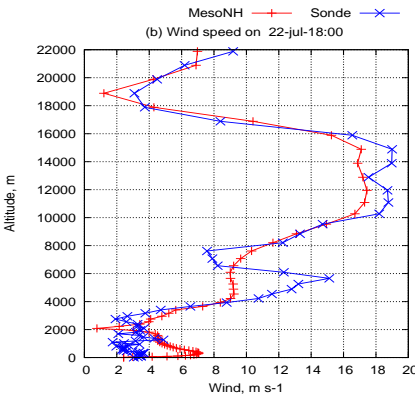

Wind, $\mathrm{m} \mathrm{s}-1$

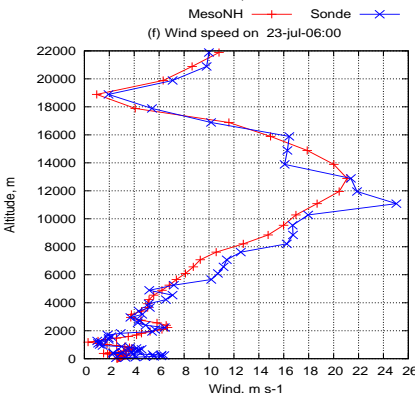

Wind, $\mathrm{m}$ s-1
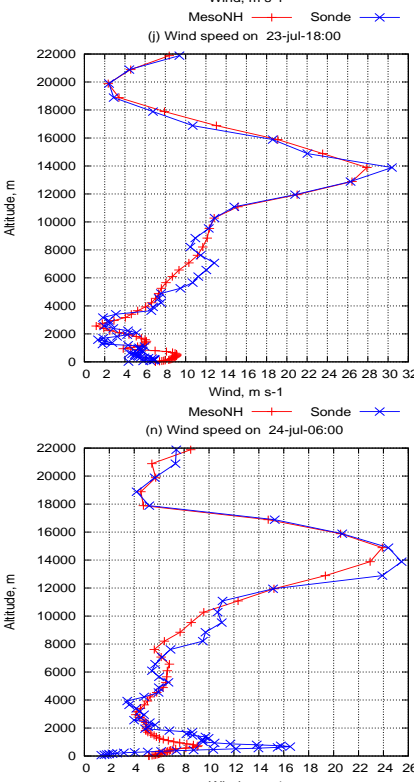
$8 \begin{array}{lll}10 & 12 & 14 \\ \text { Wind, } \mathrm{m} \mathrm{s}-1\end{array}$

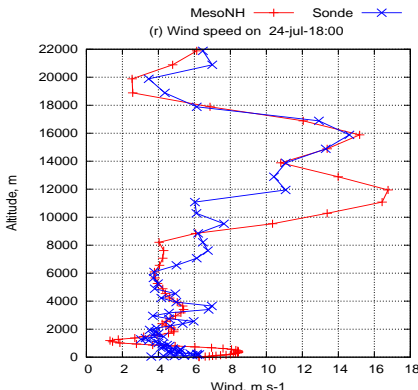

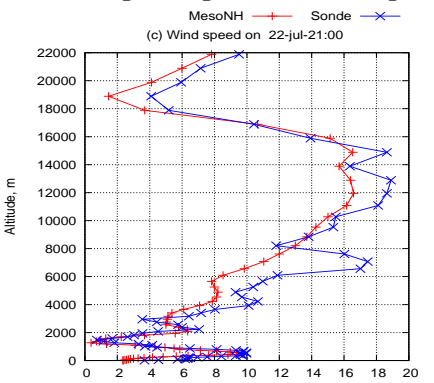

$\begin{array}{ccc}6 & 8 & 10 \\ & \text { Wind, } \mathrm{m} \mathrm{s}-1\end{array}$

MesoNH - + Sonde $x$

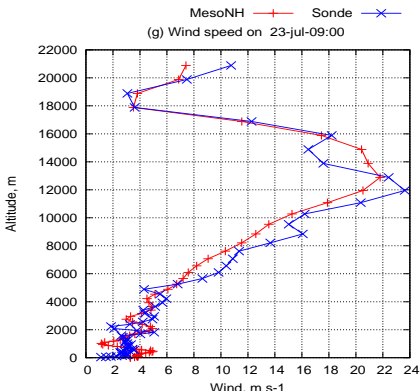

Wind, $\mathrm{m} \mathrm{s}-1$
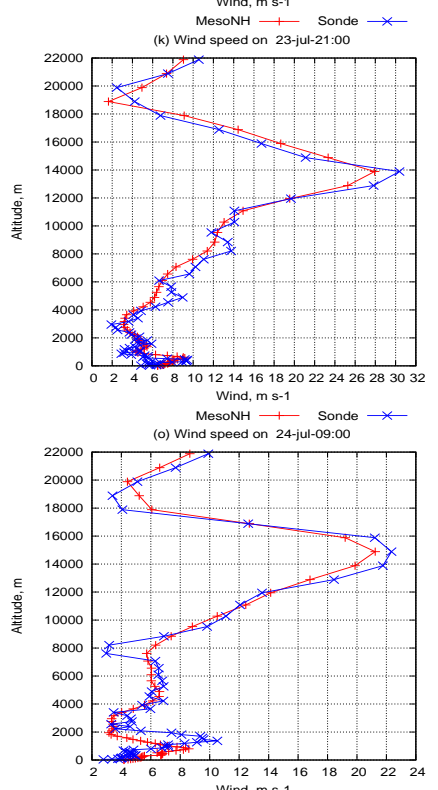

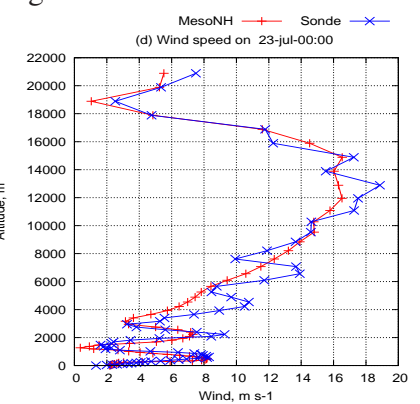

$\begin{array}{lll}8 & 10 & 12 \\ \text { Wind, } \mathrm{m} \mathrm{s}-1\end{array}$

MesoNH - + Sonde $-x$
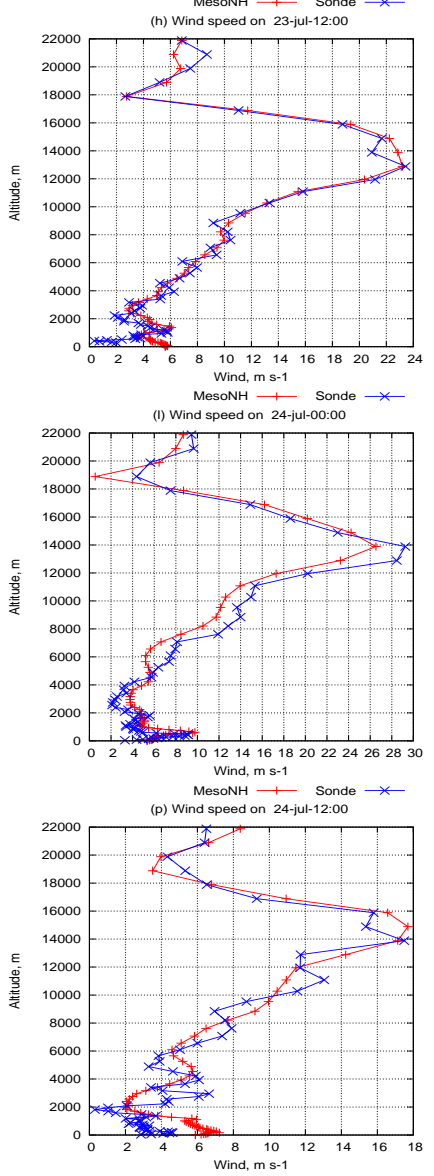
Figure S3. Comparison of Meso-NH and radiosonde relative humidity profiles. Each plot represents corresponding balloon launch.
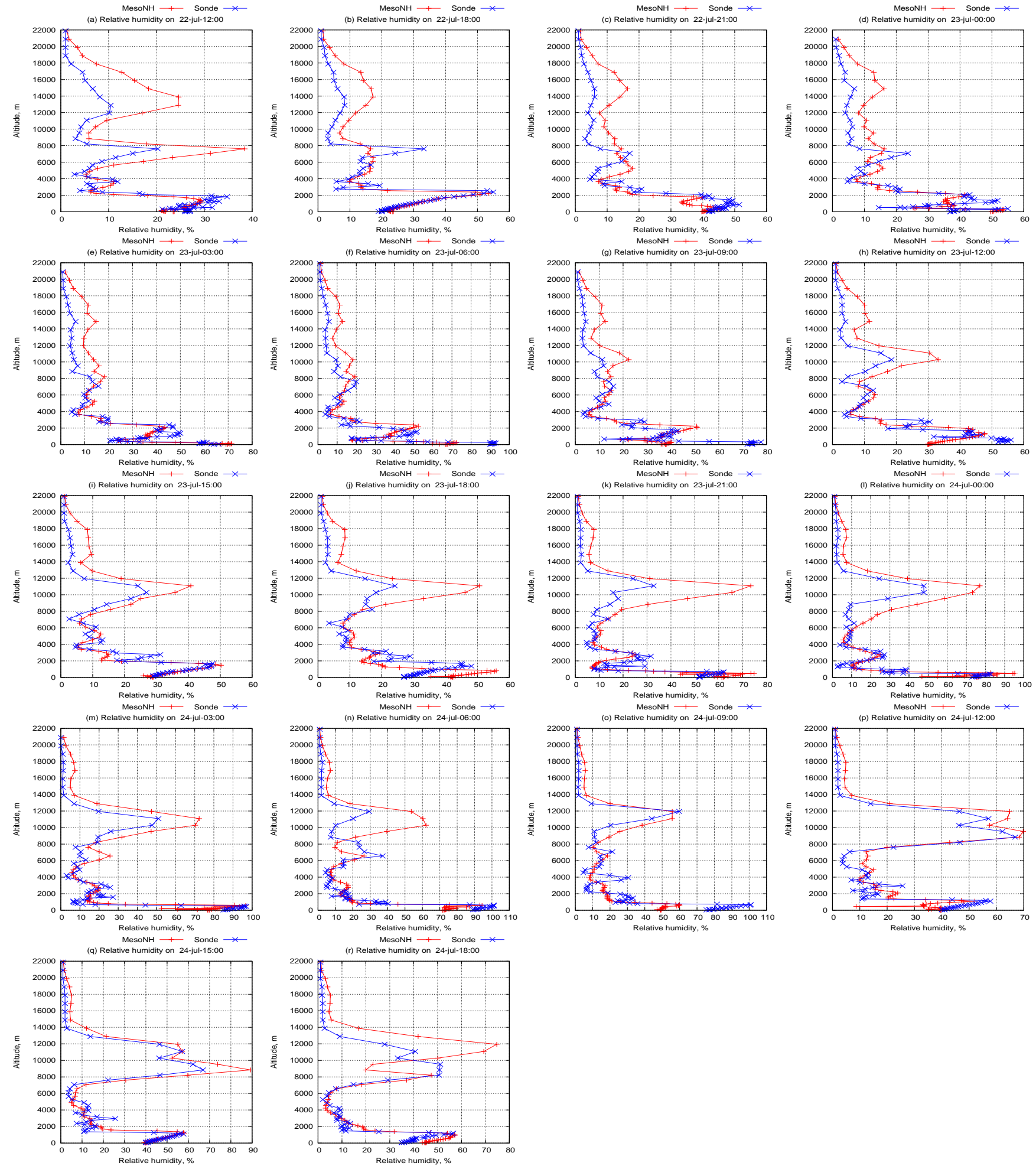
Figure S4. East-West direction cross-sectons along $38.215^{\circ} \mathrm{N}$ (crosses the lake near Montante platform) of potential temperature (filled contours) and projection of wind (arrays), at different time (06:00 - 22:00 UTC, indicated in the top of each figure) in LAKE1 experiment at $250 \mathrm{~m}$ horizontal resolution. The wind vertical and horizontal scales are indicated in the upper right corner of each figure. Blue line on the surface level indicates the location of the reservoir.
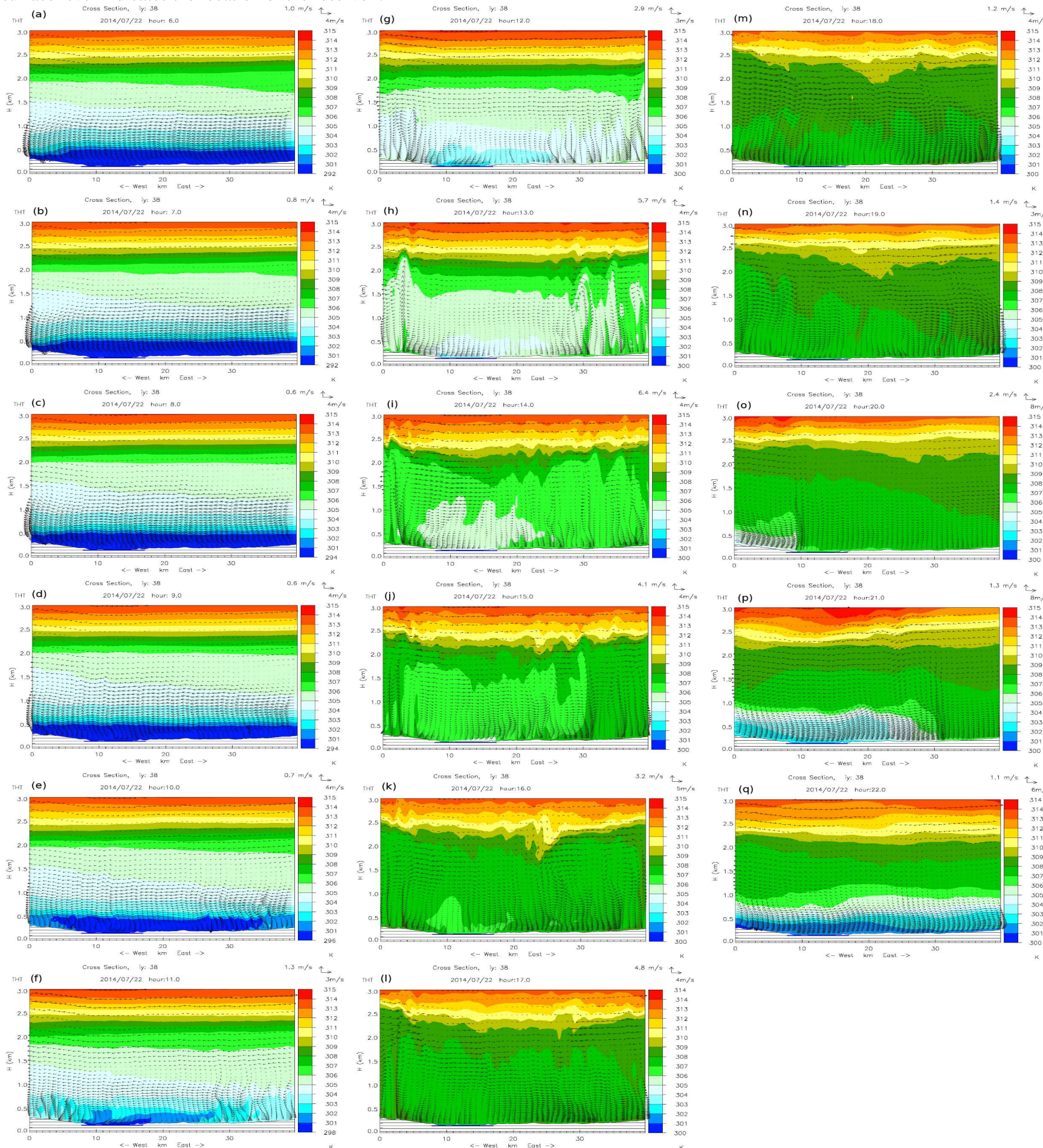
Figure S5. East-West direction cross-sections along $38.215^{\circ} \mathrm{N}$ with the difference (LAKE1 and LAKE0 simulations) of water mixing ratio (filled contours), and projection of wind (arrays) in LAKE1 experiment at 250 m horizontal resolution at different time (06:00 - 22:00 UTC, indicated in the top of each figure). Blue line on the surface level indicates the location of the reservoir.
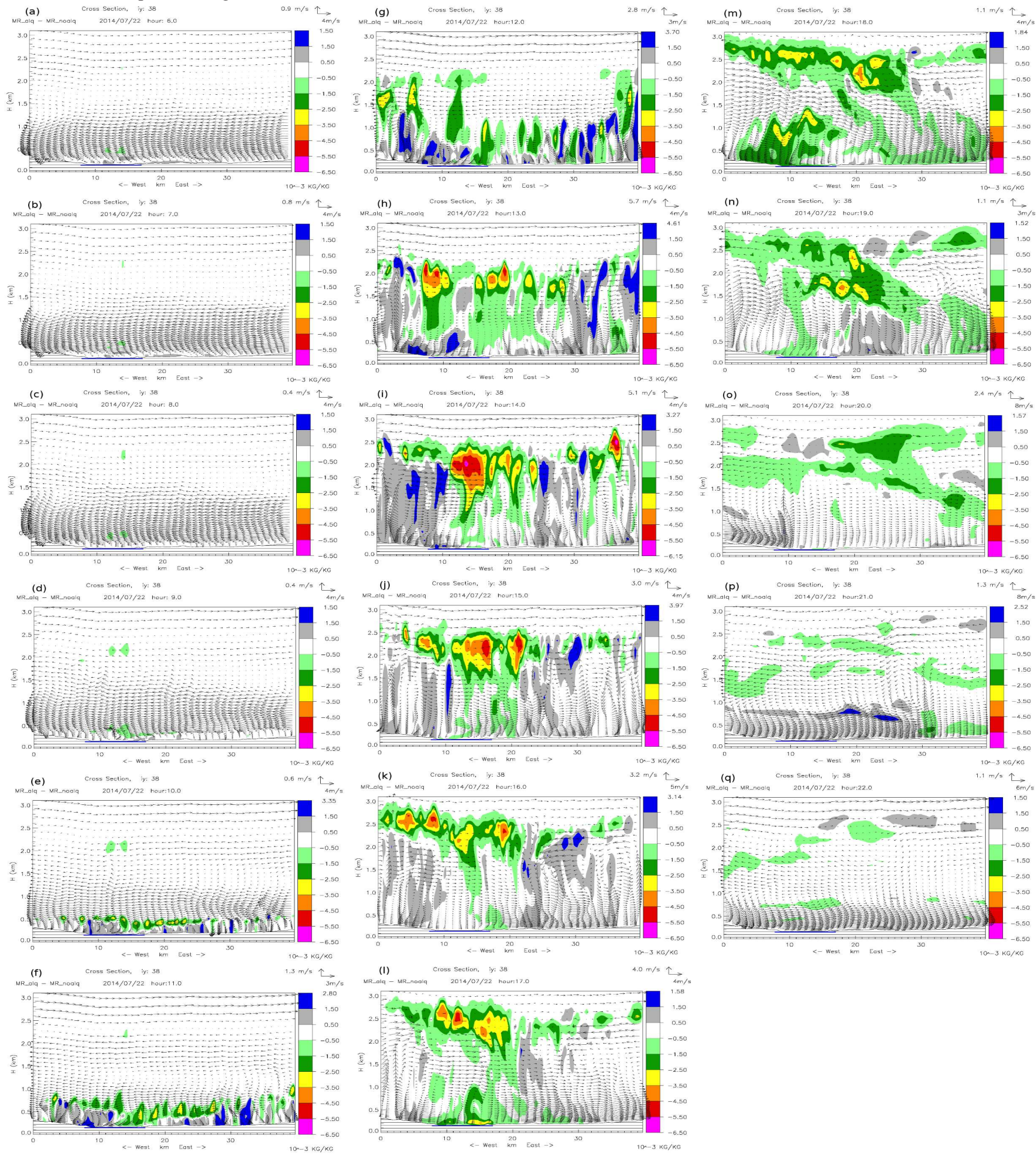
Figure S6. East-West direction cross-sections along $38.274^{\circ} \mathrm{N}$ with the difference (LAKE1 and LAKE0 simulations) of water mixing ratio (filled contours), and projection of wind (arrays) in LAKE1 experiment at 250 m horizontal resolution at different time (06:00 - 22:00 UTC, indicated in the top of each figure). Blue line on the surface level indicates the location of the reservoir.
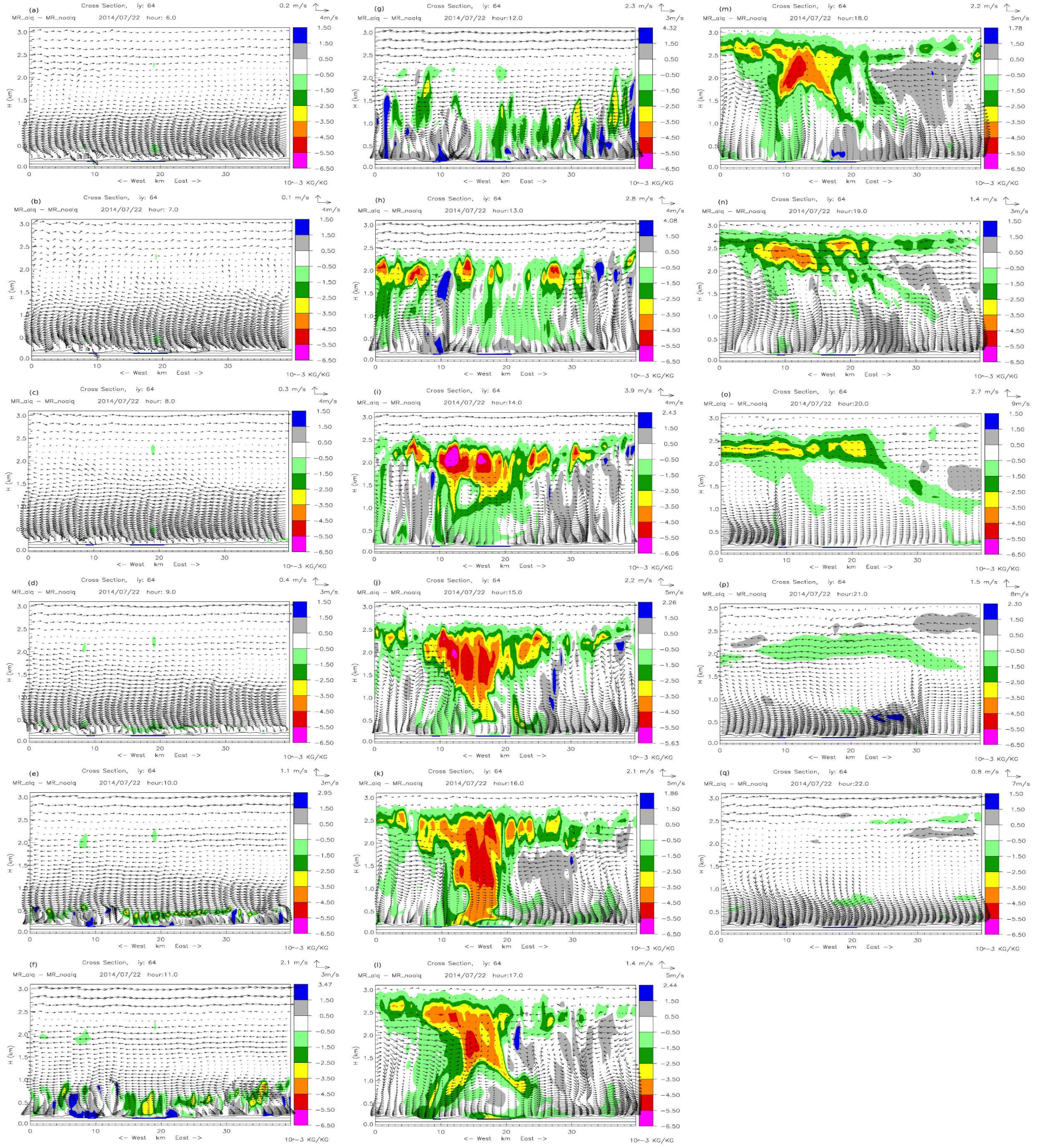